\title{
Pyridinium-N-(2-pyridyl)aminides: A Selective Approach to Substituted 2-Aminopyridines
}

\author{
Rosa Carceller, Jose L. García-Navío, María L. Izquierdo and Julio Alvarez-Builla ${ }^{*}$
}

Departamento de Química Orgánica, Universidad de Alcalá de Henares, 28871 Alcalá de Henares, Madrid, España.

\begin{abstract}
Differently substituted 2-aminopyridines have been prepared in two steps from pyridinium-N-(2-pyridyl)aminide, by reaction with the corresponding electrophiles and reduction of the $\mathrm{N}-\mathrm{N}$ bond.
\end{abstract}

As the body of knowledge about the reactivity of azinium $N$-ylides expands, the interest in such compounds as building blocks for the synthesis of heterocyclic derivatives continuously increases. ${ }^{1}$ Some of our work in the field has been concerned with the synthesis of heteroaryl-stabilized cycloiminium ylides as a way of producing highly stable dipoles, with heterocyclic moieties of unusual reactivity. ${ }^{2}$

In this paper we wish to report our first results with the pyridinium- $\mathrm{N}$-(2-pyridyl)aminide $\mathbf{1}$ in which there is a negatively charged 2 -aminopyridine fragment. The precursor pyridinium bromide was prepared by using the method of Beyer, ${ }^{3}$ and converted into the stable aminide 1 by treatment with $\mathrm{K}_{2} \mathrm{CO}_{3} /$ acetone. The structure of $\mathbf{1}$ in solution showed an intramolecular hydrogen bond as indicated, which has been described for related compounds. 4

Fig. 1

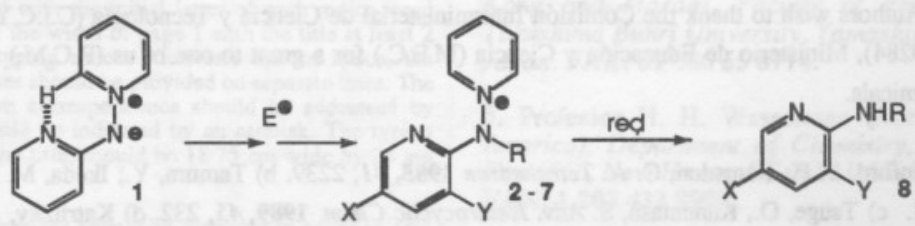

Because of its structure in solution, reaction of 1 with alkyl halides produced regioselective alkylation on the exocyclic nitrogen (compounds 2, Fig. 2), with no signs of alkylation on the N1 of the 2-pyridyl ring.

Reaction of 1 with electrophiles producing C-substitution was obtained under very mild conditions. Thus, iodination with equimolar amounts of iodine at room temp., yielded the monoiodo salt $3(61 \%)$, while when iodination was made in the presence of base $\left(\mathrm{K}_{2} \mathrm{CO}_{3}\right)$, the initially formed 3 was deprotonated and attacked again, being the diiodo betaine 4 isolated (22\%). On treatment with bromine, the process was out of control, being obtained then a mixture of 5-bromo and 3,5-dibromo salts (1:4), even when working at $0^{\circ} \mathrm{C}$. Again, in the presence of base, only the 3,5-dibromo betaine 5 was obtained (75\%). 
Other electrophiles were tested against $\mathbf{1}$. Thus, phenyldiazonium chloride produced the diazo compound 6 as a red solid (50\%). Reactions with Michael substrates were not successful, due to the good leaving

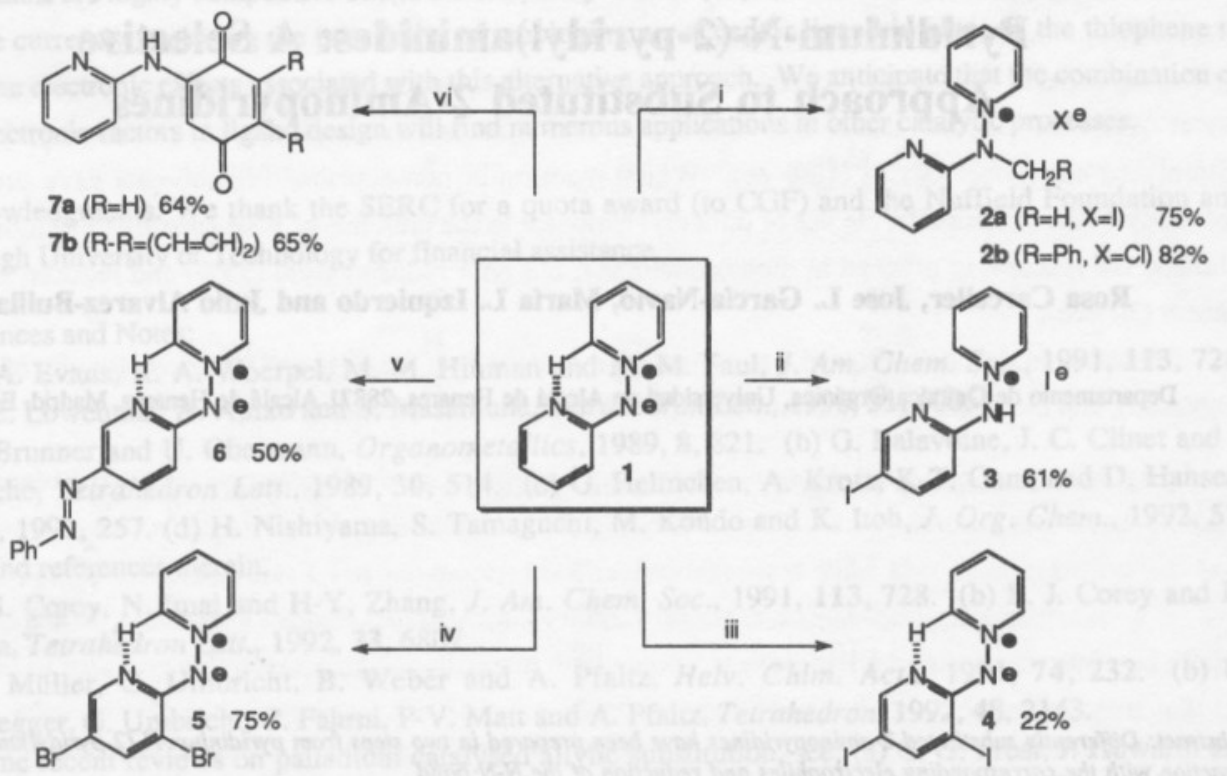

Fig. 2 Reagents and Conditions; i) Mel/acetone, r.t. or $\mathrm{BzCl} /$ toluene, reflux; ii) $\mathrm{I}_{2} / \mathrm{CH}_{2} \mathrm{Cl}_{2}$; iii) $3 \mathrm{I}_{2} / \mathrm{K}_{2} \mathrm{CO}_{3} / \mathrm{CH}_{2} \mathrm{Cl}_{2}$, r.t.; iv) $2 \mathrm{Br}_{2} / \mathrm{K}_{2} \mathrm{CO}_{3} / \mathrm{CH}_{2} \mathrm{Cl}_{2}$, r.t.; v) $\mathrm{PhN}_{2}{ }^{+} \mathrm{Cl} /$ water, r.t.; vi) Quinone/silica/ $\mathrm{CH}_{2} \mathrm{Cl}$, r.t.

character of the aminide, but with quinones the initial adduct eliminated pyridine as described in a related process by Kakehi, ${ }^{5}$ when silica gel was used as catalyst. Thus quinone adducts $7 \mathbf{a}(64 \%)$ and $7 \mathrm{~b}(65 \%)$ were obtained. Finally, cleavage of the $\mathrm{N}-\mathrm{N}$ bond was carried out using a $\mathrm{Zn} /$ acetic acid reduction system, ${ }^{6}$ and in this way the corresponding 2 -aminopyridines $\mathbf{8}$ were obtained with yields .

In summary, the use of heteroaryl-stabilized azinium aminides provides an easy, mild and selective approach to diferently substituted 2-aminopyridines. Further experiments are in progress to extend the process as a general methodology to other azines.

Acknowledgements. Authors wish to thank the Comisión Interministerial de Ciencia y Tecnología (C.I.C.Y.T.) for financial support (Proj. PB 90-0284), Ministerio de Educación y Ciencia (M.E.C.) for a grant to one of us (R.C.M.) and ALTER S.A. for a generous gift of chemicals.

\section{References.}

1. a) Ollis, W. D.; Stanford, S. P.; Ramsden, C. A. Tetrahedron 1985, 41, 2239. b) Tamura, Y.; Ikeda, M. Adv. Heterocyclic Chem. 1981, 29, 71. c) Tsuge, O., Kanemasa, S. Adv. Heterocyclic Chem. 1989, 45, 232. d) Katritzky, A. R.; Lam, J. N. Heterocycles 1992, 33, 1011 on N-Oxides and N-Imides.

2. Cuadro, A. M., Novella, J. L., Molina, A., Alvarez-Builla, J., Vaquero, J. J. Tetrahedron 1990, 46, 6033.

3. Beyer, H., Thieme, E. J. Prakt. Chem. 1966, 31, 293.

4. Spitsin, N. V., Kochkanyan, R. O. Kim. Geterotsikl. Soedin. 1989, 626.

5. Sasaki, T., Kanematsu, K., Kakehi, A. Tetrahedron 1972, 28, 1469.

6. Timpe, H.-J., Z. Chem. 1972, 12, 333. 